\title{
Blockchain in the Tourism Industry-A Review of the Situation in Croatia and Macedonia
}

\author{
Aleksandar Erceg ${ }^{1, *(D)}$, Jovanka Damoska Sekuloska ${ }^{2}$ and Ivan Kelić ${ }^{1}$ (D) \\ 1 Faculty of Economics, J. J. Strossmayer University of Osijek, 31000 Osijek, Croatia; ivan.kelic@efos.hr \\ 2 University of Information Science and Technology St. Paul the Apostle, 6000 Ohrid, Macedonia; \\ jovanka.damoska@uist.edu.mk \\ * Correspondence: aleksandar.erceg@efos.hr
}

Received: 14 January 2020; Accepted: 12 February 2020; Published: 13 February 2020

\begin{abstract}
As one of the most interactive economic activities, tourism has improved significantly since the Internet allowed customers (travelers) to look for and create their trips without the need to go to a travel agency. Through the development of Internet marketing, tourists are able to receive information in real-time and view them on the screens of their devices (computers, laptops, mobile phones or tablets), and consequently they can create their own content and share it with others. Due to this development, we are witnessing a new phenomenon, so-called app capitalism, in which companies like Uber and Airbnb make money on services and goods they do not own and finding new business models in the tourism sector which enable customer-to-customer models. To be able to respond to these changes, the tourism industry needs to bring together knowledge, money, and technology for the purpose of creating new business models. The development of technology in all social spheres, including tourism, has provided a strong tool for consumers in terms of both acquiring and disclosing information to others. One of the rapidly growing technologies which is also one of the cutting-edge technologies entering tourism is blockchain. Blockchain technology captured worldwide attention in 2017 and its implementation has been revolutionizing various industries (e.g., retail, healthcare, tourism). The aim of this paper is to analyze the potential of the tourism industry in terms of blockchain implementation. Blockchain technology provides significant benefits to the tourism industry since its implementation can help increase competitive advantage, improve customer satisfaction and enhance performance. In this paper, the authors present the current situation in the Republic of Croatia and the Republic of Macedonia regarding the use of blockchain technology in the tourism industry. The main findings of this paper comprise the detection of key areas regarding why blockchain technology is not implemented in the tourist industry, and what processes should be handled. By presenting a case study of the implementation of blockchain technology in tourism, the authors analyze the potential of using blockchain technology in the tourism industry and discuss topics for further research.
\end{abstract}

Keywords: blockchain; tourism; development review; Croatia; Macedonia

\section{Introduction}

The tourism industry represents one of the main sectors in worldwide economic development. The definition of tourism that is accepted in most of the countries is the one proposing that tourism comprises the activities of persons travelling to and staying in places outside their usual environment for not more than one consecutive year for leisure, business and other purposes not related to the exercise of an activity remunerated from within the place visited [1]. In 2018, the total tourism industry contribution to the world economy was 8.8 trillion USD [2], which represents $10.4 \%$ of the global Gross Domestic Product (GDP), $6.5 \%$ of the total global exports, $27.2 \%$ of the total services exports and $10 \%$ of 
the total world employment. It is important to state that, in this report, the World Travel and Tourism Council forecasted a further $3.6 \%$ growth in 2019, which exceeds the projected global economic growth of $2.9 \%$.

Many researchers agree that information technology has profoundly changed marketing activities [3], and these changes are also apparent in tourism. Tourism has changed significantly from the moment the Internet granted travelers the possibility to look for and organize their trips without the need to visit a travel agency. Today's tourism is characterized by improving quality as well as a variety of services, all of which are a consequence of the omnipresence of media and readily available modern technologies. Colombo and Bagiio stated that the tourism sector needs to combine technology, knowledge, and money for building innovative and new platforms to satisfy the customer (traveler) needs [4]. The tourism industry will change soon by means of digitalization, which will be triggered by shifting demands and requirements of travelers in relation to tourism products and services [5]. The global-scale changes, fierce competition and digital disruption that globally recognizable tourism brands are facing are pushing companies to develop and adopt innovations that will keep them competitive [6]. Additionally, the tourism and hospitality industries are being influenced by slim profit margins, liberalized interest rates, and differing levels of earnings, which are significantly affecting travelers' income available for traveling $[7,8]$.

As an innovative technology, blockchain is influencing changes in all sectors, including tourism. Iansiti and Lakhani [9] stated that blockchain technology represents a digital ledger that allows separate companies to do business in a transparent and trustful way without the necessity of the central node of control. This is a new way of organizing, recording, and processing information in blocks which are provable, reliable and long-lasting [10]. Rejeb and Rejeb [11] stated that blockchain will influence tourism by building trust with the following components: transparency, control, influence and recourse. Another impact of blockchain technology can be seen in the improved identity management and more efficient communication with travelers that can be used within the whole range of the tourism sector [12,13]. The use of blockchain technology in tourism can result in cost reduction connected with currency exchange rates and it has huge potential for simplifying frequent traveler loyalty programs [14]. Researchers and practitioners are looking for approaches as to how to adjust these changes in the tourism sector, bearing in mind that the traveler experience is one of the most important topics [15].

The main goal of this paper is to investigate the application of blockchain technology in the tourism industry and to check if tourism companies in Croatia and Macedonia are considering its use for their everyday operations. Blockchain is a relatively new technology on the market and, like most technologies, it has been very quickly embraced by users. This is supported by the fact that most users have encountered blockchain due to a growing trend in cryptocurrency development. It is necessary to point out that the whole industry is still learning about the application of the technology mentioned and there are relatively few applications of the technology throughout the system. In most cases, these are isolated examples made by individual business entities rather than addressing strategic issues. Blockchain technology is present and widely accepted; it is important to explore how this technology can enhance business activities. The second section of the paper gives a literature review of blockchain technology, while Section 3 provides a literature review related to the use of blockchain technology in tourism. Several examples of blockchain technology used in the global tourism industry are presented in the fourth section. In Section 5, the paper examines the use of blockchain technology in the tourism industries of Croatia and Macedonia. Based on research results, the final section of the paper presents conclusions and suggestions for further research.

\section{Blockchain-Preliminaries and Related Works}

Blockchain refers to a collection of data and transaction data that are chronologically recorded and tracked through a distributed public ledger network $[16,17]$. The information and hash (cryptographic proof) collection is called a block. These blocks, when linked together, form a secure chain [18]. 
Multiple users can add to the ledger, guaranteeing, in this way, the security and correctness of the ledger. Every addition to the chain comprises exclusive identifying data (the "hash"), which are built on the previous block. Seffinga, Lyons, and Bachman [19] stated that this allows for more precision in data tracking and helps to increase security. Table 1 presents the blockchain characteristics.

Table 1. Blockchain major characteristics [16] (p. 2).

\begin{tabular}{|c|c|}
\hline Strength & Explanation \\
\hline Disintermediation & The peer-to-peer nature of the network means that a central authority is not needed. \\
\hline Security & $\begin{array}{l}\text { The use of public-key cryptography provides a high degree of confidence and security. The } \\
\text { networked nature also provides a more resilient system with no single failure point. }\end{array}$ \\
\hline Automation & $\begin{array}{l}\text { Blockchain can facilitate greater autonomous actions, such as smart contracts, increased } \\
\text { efficiency, and accuracy. }\end{array}$ \\
\hline Immutability & $\begin{array}{l}\text { The data on the network are connected to preceding data, meaning any attempt to alter data } \\
\text { requires significant adjustments to multiple areas. }\end{array}$ \\
\hline Trust & $\begin{array}{l}\text { With no third parties needed to be involved in a transaction, greater trust is possible, and } \\
\text { parties can deal directly with one another. }\end{array}$ \\
\hline Costs & Costs can be cut due to third-party removal. \\
\hline Traceability & Transactions on the blockchain network can be traced to authenticate their origin and path. \\
\hline
\end{tabular}

Blockchain technology is often perceived as a potential platform for launching new values applied in different business sectors and transactional systems [20]. Swan [21] stated that different industrial sectors have become free from skewed regulatory and licensing schemes subject to the hierarchical power structures and the insidious influence of a vested interest in the government. Blockchain can be described as an encrypted, shared and distributed database which works as an incorruptible and irreversible public database of information [22]. Wardynski [23] stated that this technology is extremely broad and can affect any range which covers different participants, in which funds or values are traded and where data guarantee is essential. It is an online platform that documents deals in chronological order and traces assets through dispersed records in a network [24,25]. These transactions can include, but are not restricted to, payments for services and products, flight or hotel bookings, receiving and sending money, etc. [26], and are authenticated by the collaboration of participants, allowing them to verify and audit transactions [27]. This technology can create a vast number of opportunities and potentials for the exchange of resources and values through automatic business interactions between business partners. The introduction of such technology enables new disintermediated business models.

The first generation of blockchain was created for cryptocurrencies only, while the latest systems provide functions of distributed computing platforms [28]. These new platforms enable the implementation of smart contracts that automatically enforce their contractual conditions and terms [29]. Table 2 presents different blockchain categories.

Table 2. Blockchain categories [21].

\begin{tabular}{cc}
\hline Category & Characteristics \\
\hline First-generation blockchain & $\begin{array}{c}\text { Cryptocurrencies-transfer, remittance, and digital payment } \\
\text { system }\end{array}$ \\
Second-generation blockchain & $\begin{array}{c}\text { Smart contracts, the entire slate of economic, market and financial } \\
\text { applications which are more complex than simple cash } \\
\text { transactions-stocks, futures, mortgages, smart contracts }\end{array}$ \\
\hline Third-generation blockchain & $\begin{array}{c}\text { Application beyond markets, finance, and currency, especially in } \\
\text { government, health and science area. }\end{array}$ \\
\hline
\end{tabular}

In the first category, blockchain referred to the development of the first cryptocurrency-Bitcoin-but soon it was found that blockchain technology can have other uses [30-33], which, inter alia, include supplies and logistics [34,35], insurance [36], healthcare [37], 
entertainment [38,39], government $[40,41]$, and tourism [42,43]. This has resulted in the second generation of blockchain-smart contracts. These self-executing and self-enforcing contracts are based on the blockchain code [44,45]. The current, third generation of blockchain is characterized by decentralized applications (DApps). These allow persons to interact with technology in more systematic and accustomed ways through browsers and smartphones [16].

Figure 1 shows five basic principles of blockchain technology which could reduce transaction costs, remove intermediaries (e.g., bankers, lawyers, etc.), and alter the economy [9].
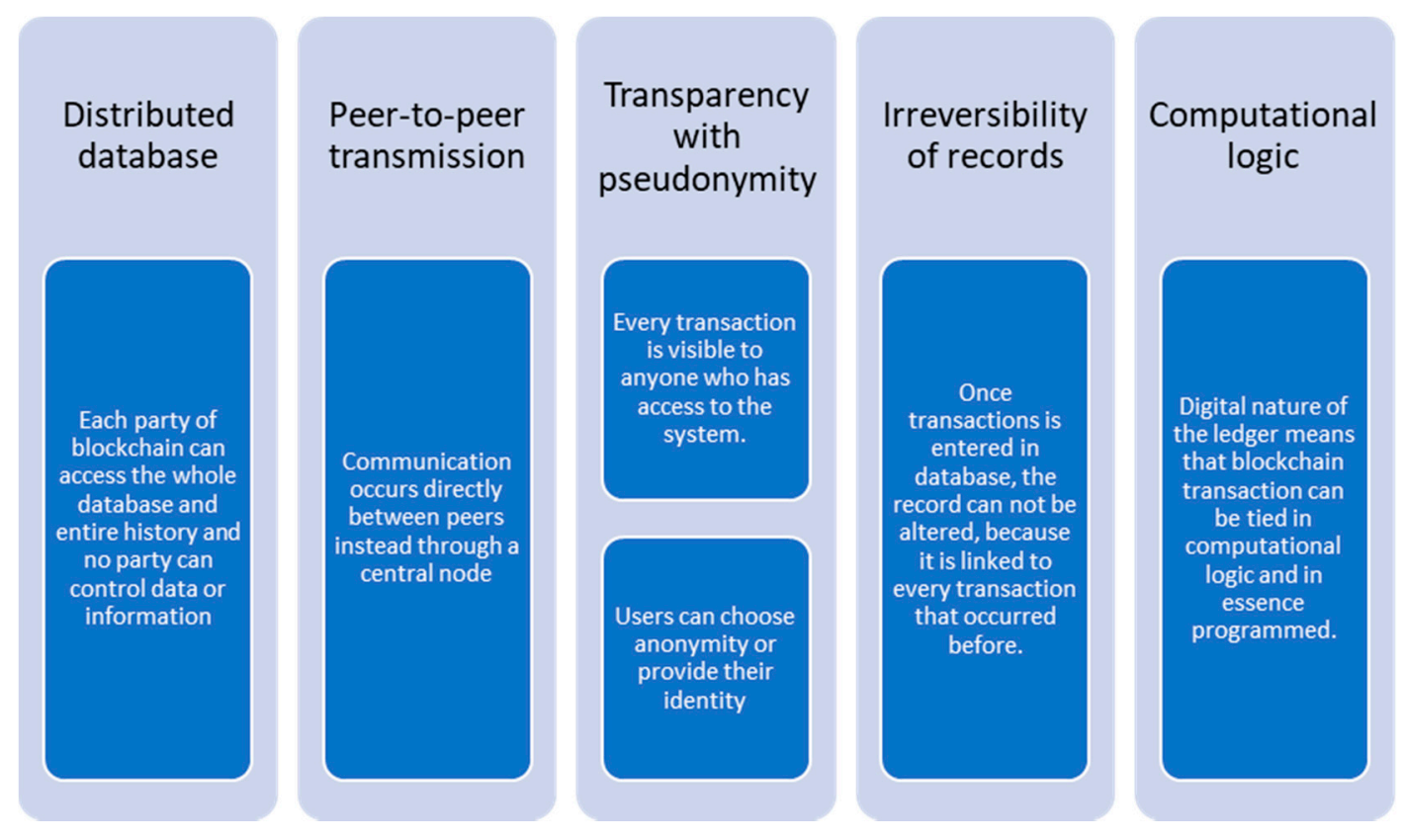

Figure 1. How blockchain works [9].

Blockchain technology can be used to reduce direct and indirect costs in transactions within the tourism industry. Shahab and Allam [46] examined the use of blockchain technology for lowering the costs which are a result of tradable permit schemes. Based upon their research results, they concluded that there are benefits of the use of blockchain smart contracts in the implementation of tradable permit schemes and that, among others, benefits include: (i) increasing the amount of relevant information available to interested actors thus reducing uncertainties; (ii) reducing the amount of irrelevant information available to interested actors thus decreasing complexities; (iii) correcting information asymmetries among the actors involved thus limiting opportunistic behaviors; (iv) lowering the need for the involvement of intermediaries thus decreasing direct monetary costs; and (v) facilitating the linkage between buyers and sellers thus improving trading quality [46] (p. 5). This research shows how smart contracts can improve the tourism industry for both parties included, i.e., tourists (customers) and providers of services (hoteliers, travel agencies, transport providers, etc.)

\section{Blockchain Application in the Tourism Industry}

The arrival of blockchain, and particularly the accomplishment of its very famous product, has generated significant media attention and created vast interest throughout numerous industries. Tourism is no exception, e.g., TUI accepting blockchain for its booking, reservation and payment system [47], and significant investments in start-up ventures in this field [48]. Through social media, customers can share their experience and satisfaction. Due to the possibility of fake reviews or frauds, this can cause problems. Blockchain can be used for solving these problems through its characteristics (security, transparency, trust, and privacy) [42]. The tourism industry was one of the leaders in blockchain investments in 2017 [49], and this trend is expected to be the same in the next three years. 
According to the report by PricewaterhouseCoopers ( $\mathrm{PwC}$ [ [49], the tourism industry, especially leisure and hospitality, are expected to receive the highest share of blockchain investments.

In addition to the practical importance of blockchain for the tourism industry, this topic is gaining interest among scholars. Floyd [50] stated that commercial use of blockchain is going to advance from an experimental stage to presenting solutions to real-world problems, where big companies will recognize the possibility of using it for finding solutions to current problems. This technology will enable many potential applications for cross-industry use which will impact the contracts, transportation, payments and supply chain management. As shown in Figure 2, this potential will present different opportunities for stakeholders in the tourism industry in terms of the possible reinvention of tourism.

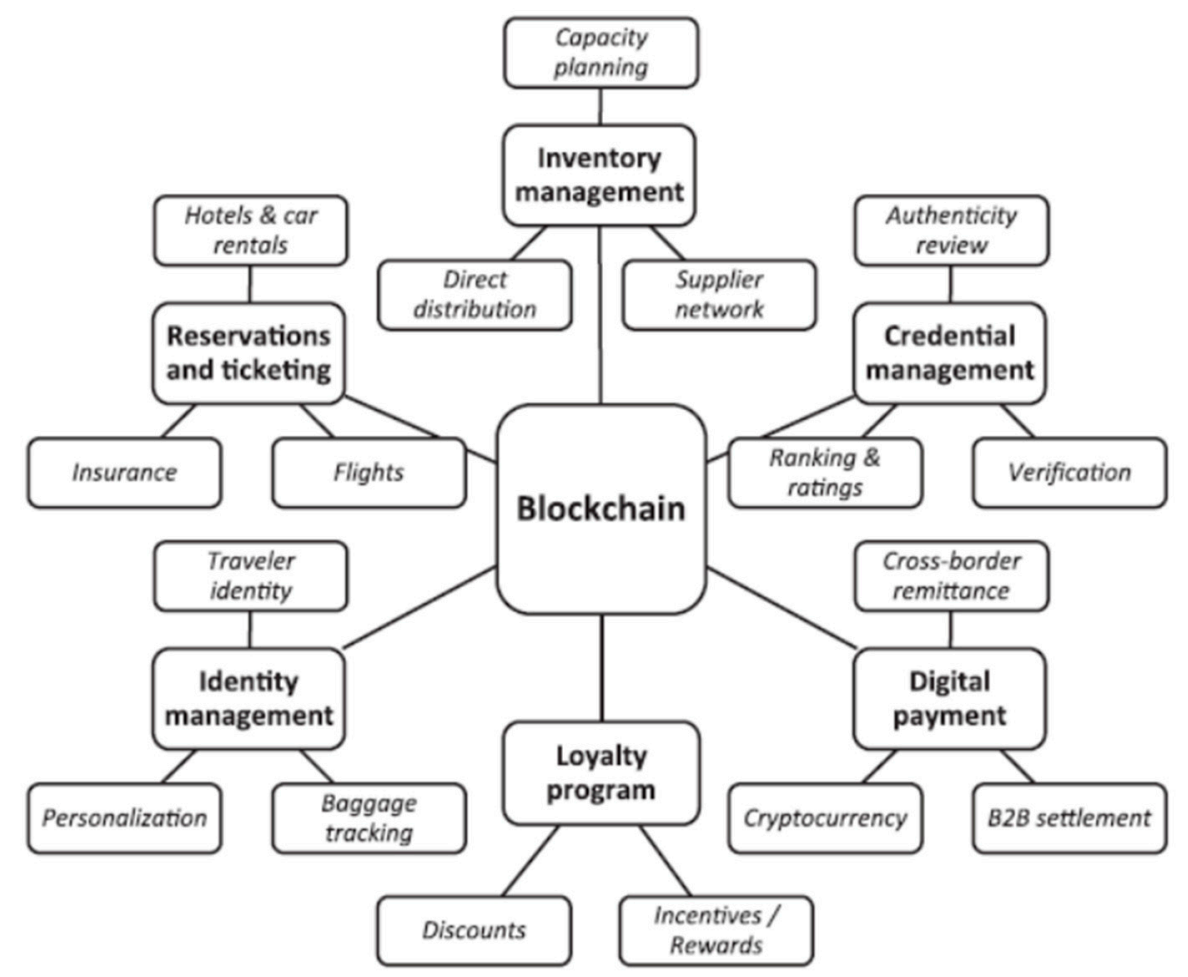

Figure 2. Overview of key blockchain applications to enhance tourism [43] (p. 3).

Blockchain is multi-faceted and its application will improve tourism in several ways: (i) it will improve the traveler experience through platform support; (ii) cross-border payments via blockchain are quick and trouble-free; (iii) the use of blockchain offers diversification by means of which it safeguards the currency and strengthens the banking system; and (iv) blockchain can contribute to lowering total operating costs [43].

Blockchain development and the blockchain second-generation trends related to the use of smart contracts could promote accumulated benefits to travelers. In [51], it was confirmed that smart tourism and smart cities share the same architecture. The authors stated that the smart tourism and smart city architecture both contain six layers, as can be seen in Table 3 . 
Table 3. Smart city and tourism architecture with blockchain [16] (p. 4).

\begin{tabular}{|c|c|c|}
\hline Layer & Smart City Components & Blockchain Components \\
\hline Traveler & $\begin{array}{l}\text { Accommodation, entertainment, } \\
\text { restaurant, shopping, } \\
\text { transportation, a heritage site. }\end{array}$ & Same as Smart city components \\
\hline Citizen & $\begin{array}{l}\text { Economy and innovation, } \\
\text { community and citizenship, } \\
\text { culture and entertainment, } \\
\text { management and transport, urban } \\
\text { places and spaces. }\end{array}$ & Same as Smart city components \\
\hline Policy & $\begin{array}{l}\text { Structure, procedure, process, } \\
\text { governance }\end{array}$ & $\begin{array}{l}\text { Additional policies for blockchain } \\
\text { across industries. }\end{array}$ \\
\hline Platform & $\begin{array}{c}\text { Platform service (apps, cloud, and } \\
\text { open application program } \\
\text { intergace (API)) }\end{array}$ & $\begin{array}{c}\text { Diverse cryptocurrencies } \\
\text { (coin/token) and smart contracts, } \\
\text { DApps, Exchange markets for } \\
\text { cryptocurrency. }\end{array}$ \\
\hline Data & Urban data (heterogeneous data) & Distributed hyperledger database \\
\hline Information technology (IT) & $\begin{array}{c}\text { Infrastructure components same } \\
\text { as Smart city }\end{array}$ & Ubiquitous city network \\
\hline
\end{tabular}

Based on Table 3, it can be concluded that the Traveler layer in smart tourism is above the Citizen layer and that the first four layers share the same components. Thus, it can be concluded that smart tourism is the expansion of smart cities. Nam [16] states that tourism will embrace technology developments which will influence and change the way the business is done today. Based on analyses of today's practice, three fields of improvement are recognized: (i) cost reduction, (ii) cryptocurrency adoption, and (iii) developing new eco-systems. The use of blockchain in tourism would simplify many processes which regular tourists need to go through when organizing their trips (booking, arrival, staying). This technology will simplify and speed up the process of checking travelers at ports, airports and in all other means of transport. Since blockchain is a decentralized system, the traveler will need to identify him/herself only once before boarding and the reason for that lies in the fact that all traveler-related information and transactions are dispersed in several places.

There are several benefits of blockchain technology for all sectors of the tourism and hospitality industry. They include: (1) secure and transparent transactions, (2) the ease and speed of retrieving and reviewing past transactions, (3) elevating and promoting a level of trust and confidence among blockchain participants, (4) improving customer/guest satisfaction, and (5) promoting a higher degree of sophistication and innovation within the hospitality and tourism industry [52] (p. 119). As can be seen in Figure 3, Önder and Treiblmaier [42] presented in their research three research propositions to be further investigated and examined by the tourism research society.

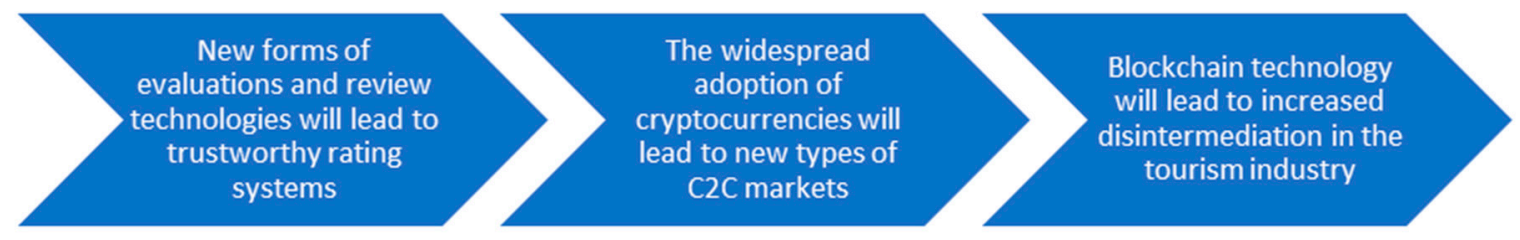

Figure 3. Research proposals [42].

In addition to the Önder and Treiblmaier [42] research, Kizildag et al. [53] examined the potential of blockchain technology in the tourism and hospitality industry and identified the following areas: (i) payment and cryptocurrencies; (ii) tracking and service customization; (iii) disintermediation of hospitality and tourism operations; (iv) innovative loyalty programs; (v) smart contracts; (vi) integrated property management systems; (vii) verified rating and review systems; (viii) collaborative initiatives 
and due diligence; and (ix) smart cities and smart tourism. Each of these areas of blockchain technology used in the tourism and hospitality industry has attracted interest from many researchers.

Since the investments in blockchain solutions to the tourism industry are on the rise, these improvements are expected to have a considerable impact on the future of tourism and the way the processes are to be handled. Thus, it is important for tourism researchers to start and continue to research the use of blockchain technology in tourism from different viewpoints in order to create both appropriate and thorough research proposals and explanations [42]. Kizildag et al. [53] (p. 14) stated that there is a critical need for extensive academic exploration by hospitality and tourism scholars to collaborate with industry practitioners.

\section{Examples of Using Blockchain Technology in Tourism in the World}

Preece and Easton [54] stated that, by 2025, blockchain technology will become an important and central element for businesses. Thus, one can state that all parts of the tourism and hospitality industry will also be affected by the innovation and applicability of blockchain technology. The use of blockchain technology changes the travel experience, but its implementation poses many challenges that must be tackled to benefit more and more tourists in the future. The tourism market is one of the most complex markets. Every year, the wishes, expectations, and needs of tourists change, and thus they become more demanding.

With technological development and progress in every respect, we can conclude that soon, the tourism market will, maybe completely, switch to blockchain technology. Many experts are already working on individual projects to develop artificial intelligence applications that will be able to use collected and stored data to predict user preferences and provide accurate recommendations to their users. Table 4 provides examples of blockchain technology in the travel experience and travel planning.

Table 4. Blockchain examples [55-60].

\begin{tabular}{cc}
\hline Example & Characteristics \\
\hline Winding Tree & $\begin{array}{r}\text { It is aimed at eliminating travel agents such as Expedia and eDreams. The goal is to } \\
\text { connect travelers directly to service providers such as airlines and travel companies, } \\
\text { with minimal passenger fees, while reducing service providers' costs. }\end{array}$ \\
\hline Cool Cousins & $\begin{array}{r}\text { It aims to help travelers shorten the search process with on-demand counseling that } \\
\text { suits their unique needs. Identifying the region's most important areas and } \\
\text { potential attractions cover much of the planning process. }\end{array}$ \\
\hline Deskbell Chain & $\begin{array}{c}\text { Its main goal is to create a special model of interaction between businesses and their } \\
\text { clients in the field of tourism. The project will unite not only hotels and their guests } \\
\text { but also the closest institutions and local businesses into a unique ecosystem of } \\
\text { mutual motivation. This will allow all participants to distribute and exchange } \\
\text { services, offers, and events. In this case, the motivation reward will be the Deskbell } \\
\text { (DBT) units of the digital currency. }\end{array}$ \\
\hline TravelChain & $\begin{array}{c}\text { Decentralized data exchange platform in the travel market where users enter their } \\
\text { personal information and receive benefits for it. Created by a handful of } \\
\text { professionals whose mission is to create equal access to all users involved in the } \\
\text { exchange of information and being able to control their personal information } \\
\text { they enter. }\end{array}$ \\
\hline FlightDelay & $\begin{array}{c}\text { Uses smart contracts for full automation of the signing and paying process for flight } \\
\text { insurance policies. }\end{array}$ \\
\hline WebJet & \begin{tabular}{c} 
Started with blockchain to create a chain of smart contracts for hotel reservation \\
\hline
\end{tabular}
\end{tabular}

Creating a global database containing the most comprehensive and unbiased information on the suppliers and users in the travel market, and the travel and tourism experience, would give a whole new meaning. Blockchain-built databases would not only be accessible to large corporations, but also to small and large businesses. 
One of the areas which will be heavily influenced by the implementation of blockchain technology are loyalty programs. Kowaleski, McLaughlina and Hill [14] state that companies involved in the travel industry will need to: (i) participate in the process of defining currency exchange processes between different loyalty programs, (ii) seek to maintain exclusive control over their data, and (iii) get guarantees that the platform would remain impartial. The emerging status of blockchain for loyalty programs represents a chance to recognize the importance of disruption and to shape its future effects.

\section{Materials and Methods}

This paper presents the research conducted on the use of blockchain technology in the tourism industry in Croatia and Macedonia. For the preparation of the theoretical framework, a review of available scientific and professional papers and sources was examined. For the empirical part of the paper, i.e., a review of the current status of the use of blockchain technology in the tourism industry in Croatia and Macedonia, the authors examined and collected data already available in both countries.

The authors compared the use of blockchain technology in the tourism industry in Croatia and Macedonia since in both countries the tourism industry plays an important role in the national economy and there is a need for improving services for their users (i.e., tourists). It is important to note that the field referring to the use of blockchain technology in the tourism industry in these two countries is still insufficiently researched.

In our research, we used secondary data collected by online searches using the following two search phrases: "blockchain in tourism Croatia" and "blockchain in tourism Macedonia". By means of these online searches, we obtained secondary data and information which we used to present the use of blockchain in tourism in the countries under study. The authors gather secondary data and analyze two countries (Croatia and Macedonia) and according to search results, it can be concluded that other countries in the region are similar. Based on search results, the authors presented few available applications of blockchain in the countries under study and the situation related to the infrastructure needed for future implementations. Although the authors examined only two countries in the research of this paper, the main limitation is data accessibility, since there are no examples at all or there are no successful examples of the use of blockchain technology.

\section{Blockchain in Tourism-Challenges and Opportunities}

\subsection{Blockchain in the Croatian Tourism Industry}

The basic characteristics of tourism today are to travel faster, cheaper and easier, and to offer not only a better quality, but also a variety of services. In recent years, the goal of creating travel content has seen the transformation of tourist destinations to offer more than a family vacation, more than summer and more than sun and sea. Croatian tourism is still characterized by the following [61] (p. 19):

- Insufficient differentiation of products and services;

- Lack of innovative accommodation facilities of good quality;

- Static system of national marketing;

- Lack of globally branded tourist destinations;

- Inherited orientation of the local population towards seasonal business.

In the future, Croatia will focus on five groups of geographic markets and, along with the traditional target segments 'families with children' and 'golden age', it will be significantly more agile in relation to other consumer segments characterized by travel styles and preferences for a wide range of products, the prolongation of the tourist season and consumption growth. Generally, it is the tourists who mostly organize their trips independently, looking for models like blockchain technology that will allow them to easily organize the trip. Croatian tourism is constantly growing. According to eVisitor, which contains data on tourist traffic realized in commercial and non-commercial objects and nautical 
charters (eCrew system), in the period from January to the end of August 2019, 16.5 million arrivals $(+5 \%)$ and 90.1 million overnight stays $(+2 \%)$ were made. Foreign tourists made 14.7 million arrivals $(+5 \%)$ and 79.1 million overnight stays $(+1 \%)$, while domestic tourists recorded an increase of $10 \%$ in arrivals and an increase in overnight stays of 7\% [62]. Croatia ended the tourist year with $5 \%$ more tourists and $2 \%$ to $3 \%$ more overnight stays [63].

Due to its complexity, tourism can be considered as one of the fastest growing sectors at the current time. Numerous studies have shown that the adequate use of e-marketing activities can influence the achievement of various goals of tourism activities. One of the technological trends that is increasingly being implemented in the tourism industry is certainly the use of blockchain technology since with the development of technology. Today's modern consumers, or tourists, are searching for information about a tourist destination via mobile technology in real-time, as well as before arriving at a tourist destination. The implementation of technology can be seen through the process of booking accommodation, purchasing tickets, making security checks easier, and paying with cryptocurrencies. Although the Croatian National Tourist Board follows technological trends and invests heavily in e-marketing, the entire industry is currently learning about the potential of blockchain technology. Until October 2019, Croatia was outside the European Blockchain Partnership, since the Croatian government had not signed the Declaration creating the European Blockchain Partnership [64], which narrowed the possibility of creating new projects. As the implementation of this technology is applicable to all branches of industry, e.g., energy, health, security and financial industry, all data registers, etc., Croatia has signed a statement of cooperation establishing a wide-ranging European Blockchain Partnership and the agreement [65] represents the first step by the Republic of Croatia to participate in blockchain technology development initiatives. The benefits that technology has to offer in tourism are evident in terms of instability and security. The decentralization of blockchain indicates that information can never be transmitted offline or lost due to accidental erasure or malevolent cyberattack; thus, transactions can always be monitored [66].

An example of the use of blockchain technology in Croatian tourism is the Rijeka Marketplace digital platform created by the Rijeka Tourist Board and developed on the basis of blockchain technology, which is the basic infrastructure for the development of a smart destination in the city of Rijeka and its surroundings. The Rijeka Marketplace provides destination providers with greater visibility, entrepreneurs with a platform to advertise and sell products and services, and citizens and guests with a wide selection of easily accessible city services, which are used through a digital wallet installed on a user's mobile phone. All this is possible thanks to unique blockchain technology in the background, which ensures that every transaction is as secure as possible for the provider and the consumer of the service [67]. It is important to point out that the application is an example of implementing multiple capabilities into one platform provided by blockchain technology that will evolve as a platform in the future. This platform can be used for testing and adopting the aforementioned technology in order to develop the technological infrastructure of Croatian tourism.

\subsection{Blockchain in the Macedonian Tourism Industry}

As one of the most dynamic sectors, the tourism industry has always been adapting to technological development. Digital technologies open new innovative potentials and growth opportunities for the whole tourism sector. As part of smart tourism, blockchain technology unlocks and enriches the tourism experience. As an innovative use of cryptography, blockchain technology creates features like permanent data records, the ability to identify the time and origin of every entry in a blockchain, access by all participants to all data in a blockchain and guaranteed implementation of smart contracts that are automatically executed. The challenge of the tourism industry is to absorb and implement blockchain technology to provide an enjoyable tourism experience, providing at the same time substantial efficiency to the tourism industry [68].

Tourism has shown continued expansion, outpacing the global economy. Tourism exports grew faster than merchandise exports, driven by the most favorable economic environment, technological 
advances, and new business models. According to the World Tourism Organization (UNWTO) data, the international tourist arrivals grew by $5 \%$ in 2018, reaching 1.4 billion [69]. An analysis of tourism in the Republic of Macedonia revealed that more than 1.2 million arrivals were recorded in 2018. More than 700,000 arrivals account for foreign tourist arrivals. Compared to 2017 , there is an increase of $12.8 \%$ and $12.1 \%$ in the number of tourist arrivals and the number of foreign tourists, respectively. Remarkable growth is also noticed in the number of overnight stays. As seen in Table 5, in comparison with 2017, total overnight stays and foreign overnight stays increased in 2018 by $14.5 \%$ and $15.2 \%$, respectively.

Table 5. Tourist arrivals and overnights in the Republic of Macedonia in the period 2010-2018 [70].

\begin{tabular}{ccccc}
\hline \multirow{2}{*}{ Year } & \multicolumn{2}{c}{ Tourist Arrivals } & \multicolumn{2}{c}{ Overnight Stays } \\
\cline { 2 - 5 } & Total & Foreign & Total & Foreign \\
\hline 2010 & 586,241 & 261,696 & $2,020,217$ & 559,032 \\
2011 & 647,568 & 327,471 & $2,173,034$ & 755,166 \\
2012 & 663,633 & 351,359 & $2,151,692$ & 811,746 \\
2013 & 701,794 & 399,680 & $2,157,175$ & 881,375 \\
2014 & 735,650 & 425,314 & $2,195,883$ & 922,513 \\
2015 & 816,067 & 485,530 & $2,394,205$ & $1,036,383$ \\
2016 & 856,843 & 510,484 & $2,461,160$ & $1,054,017$ \\
2017 & 586,241 & 261,696 & $2,020,217$ & 559,032 \\
2018 & 647,568 & 327,471 & $2,173,034$ & 755,166 \\
\hline
\end{tabular}

The total contribution of travel and tourism to the GDP value of Macedonia in 2018 was $7.2 \%$, which represents a rise of $5.8 \%$ compared to the previous year [71]. According to the Travel and Tourism Competitiveness index, tourism destination competitiveness is a comprehensive set of factors and policies that enable sustainable development. It involves enabling environment, policy and enabling conditions, infrastructure and natural and cultural resources [72].

Attaining sustainable growth in tourism requires investments in enhancing all factors creating tourism competitiveness. The trend in tourism consumption is directed toward a higher influence of digital technologies. The rapid growth of the Internet and digital technologies has changed tourism consumer behavior and habits of making tourist and travel arrangements, the ways of searching for information, the way of settling payment transactions, etc.

The digitalization of the tourist sector in the Macedonian economy is not a result of the strategic approach because although information technology is recognized by the National Tourism Strategy of the Republic of Macedonia 2016-2021 as one of the main global trends in the tourism sector, there are no recommendations, actions, and directions toward future employment of digital technologies in the tourism sector [73].

The main digital tools used in the tourism sector in Macedonia are Web 1.0 and Web 2.0 technologies. In Macedonian tourism, the Web is a leading digital touchpoint providing only one-way communication with tourist service consumers. The web pages of the tourist service providers do not offer tools and possibilities to engage a tourist in the commercial or financial transaction activities. Social networks, together with digital marketplaces or tourist platforms like Booking.com, Airbnb.com, tripadvisor.com, trivago.com, represent a second venue for the promotion and communication between a provider and a consumer of tourist services. As part of Web 2.0 digital technology, these tools enable customer engagement and feedback referring to transaction, distribution, and promotion of services.

Currently, the Macedonian tourist sector does not show any evidence or practice of the employment of new Web 3.0 technology, represented by blockchain technology. This third generation of the Internet is a decentralized network, user-oriented and more transparent, where everyone can participate without fear of loss of privacy and security. The main reasons for a lack of experience and employment of blockchain technology could be identified in the following: lack of system regulation, lack of infrastructure or a blockchain ecosystem and lack of awareness of the tourist actors in relation to the importance of blockchain technology. 
A regulatory issue is one of the main obstacles in the employment of blockchain technology. The actual Law on Foreign Exchange Operations in Macedonia restricts investments and the use of cryptocurrencies as one of the modes of blockchain technology. The initial step in overcoming regulatory obstacles is the launching of the new payment regulation that implements the EU Payment Services Directive (PSD2). This new payment regulation would open the entrance to FinTech companies to provide innovative payment services as well as to establish and operate new payment systems [74].

A lack of infrastructure relates to the absence of a blockchain ecosystem. It refers to the lack of actors like users, miners, and developers, who interact with one another. The operation of an efficient blockchain ecosystem should also involve entities like technology companies focusing on providing and building blockchain technology for the tourism sector, the service provider category as a provider of technical professional and financial services, universities as organizations that provide research, education and training services for blockchain technologies, ecosystem supporters that involve governmental and nongovernmental associations and organizations supporting the development of blockchain technology [75].

Most of the tourist actors, i.e., service providers, in Macedonia are not aware of the opportunities and benefits related to blockchain technology. By interviewing some of the hoteliers, we found out that they have heard about the term cryptocurrencies, but they do not know how they operate. None of them are aware of other modes of blockchain technology and how they could be employed in the tourism industry and what the benefits of their employment could be. Thus, the main challenge is to boost the awareness of tourist service providers that blockchain technology is a technology trend that will change the way people travel and the way the tourist industry operates.

The employment of blockchain technology should be a strategic challenge in the tourism development of the Macedonian economy. The efforts should be focused on the creation of the favorable blockchain ecosystem which will open the door for the implementation of blockchain technology modes in the transformation of business models, especially in the tourism sector. Blockchain technology could even be considered as a product to attract tourists. The possibility to experience blockchain technology in Macedonia could aim at attracting a new niche of visitors - a member of the blockchain and cryptocurrency community, creating and promoting Macedonia as a blockchain destination.

\subsection{Future of Blockchain in Tourism in Croatia and Macedonia}

Tourism should be based on investments into applications that will provide the starting point for consumers when deciding to visit a destination or not and make it easier for tourists to stay at their destinations. The objective of the above technology and implementation in tourism enables the following [76]:

- Ease of use through an intuitive user interface and application availability across platforms,

- Openness and collective intelligence,

- Innovation through a unique and functional IT solution based on the latest blockchain technology,

- Durability, reliability, and longevity,

- Confidence as to how the process is executed, and

- Transparency and immutability.

A mistrust of the general public in relation to concerns about personal information is one of the downsides of blockchain technology, which certainly affects both development and implementation. Security systems are being developed in parallel with the development of blockchain-based technologies, which will in the future certainly result in the widespread use of the technology mentioned above in tourism to simplify travel arrangements and stays at a tourist destination.

Based upon all of the above mentioned, it is evident that blockchain technology can be successful and that it has potential in the tourism industry in Croatia and Macedonia, but there is a lack of infrastructure providing this technology to users. This paper analyzes information on potential and the implementation and proves that this technology can be most useful for collecting and processing 
data, aimed at getting information and paying for different services (i.e., accommodation capacities, simplifying calculation, registration, getting information for tourists). On the other hand, there is still an insufficient number of blockchain technology implementations in Croatia and Macedonia. Therefore, it is necessary to properly distribute marketing activities and development budgets by enabling greater market growth, considering all relevant parameters. By tracking analytical data (the number of arrivals, arrival locations, the payment system, etc.), blockchain platforms can effectively distinguish the markets with the highest growth, i.e., the country generating the largest number of tourist arrivals in Croatia and Macedonia. Based on these data, an effective marketing campaign can be created, and the budget can be allocated on a targeted basis. To achieve success in using marketing information systems, it is necessary to continually invest effort and time, but the return is what makes it profitable. Therefore, it is certainly worthwhile to invest in the implementation of this technology as a direct distribution channel created for access to information that, in the long run, leads to a competitive advantage based on relevant data.

An additional potential of blockchain technology for tourism in both countries under study is the use of ManuChain, which is based on blockchain integration into a digital twin for individualized manufacturing on a decentralized network [77] (p. 9), which can result in a new bi-level intelligence technique to achieve a bulk individualization paradigm in a manufacturing workshop. Another possibility is to use MakerChain [78] in the tourism industry. The use of this approach can allow designers from different parts of a country to design products (souvenirs) which will be produced (printed on 3D printers) at tourist locations. This approach can help to reduce product warehousing and logistic costs and to produce high-quality products for tourists much faster.

\section{Conclusions}

Blockchain technology is often perceived as a potential platform for launching new values applied in different business sectors and transactional systems. Blockchain developments and the blockchain second-generation trends in the use of smart contracts could forward accumulated benefits to travelers. This technology will simplify and speed up the process of checking travelers at ports, airports and in all other means of transport. Since the investments in blockchain solutions for the tourism industry are growing, it can be expected that these developments will have a significant impact on the future of tourism and how the processes will be handled.

Tourism has become one of the trends that millions of individuals access daily. One reason is certainly faster communication based on information and communication technology. Namely, as an economic activity, tourism defines two basic types of stakeholders: tourists who enjoy the benefits of tourism, and, on the other hand, tourism workers who use tourism as an economic activity to generate income. In this paper, we have highlighted the evidence of blockchain technology, studied previous research on the topic, and recognized examples of blockchain technology in the tourism industry. To evaluate potential benefits of blockchain technology in the tourism industry, there is a need for a broad review and methodical conceptual analysis of the implementation and application of this technology.

Thus, the overall aim of this paper was to introduce, review and present potential areas of the application of blockchain technology with a review of two countries well-known for their tourism-Croatia and Macedonia. A key element in this case is investment in new trends such as blockchain technology, which plays a significant role in the tourism industry as it is a key component that enables the aggregation of other activities to stimulate economic activities. This paper presents an example of the use of blockchain technology in Croatian tourism using the example of the Rijeka Marketplace platform. The limitations are that Croatia was outside the European Blockchain Partnership until October 2019, and certainly, tourism businesses will exploit the potential of the partnership in the upcoming tourist season. In the tourism industry in Macedonia, there is still no evidence or practice of employing the new Web 3.0 as it is blockchain technology. This third generation of the Internet is a decentralized network, user-oriented and more transparent, where everyone can participate without fear of loss of privacy and security. The main reasons for the lack of experience and employment 
of blockchain technology could be identified in the following: the lack of system regulation, lack of infrastructure or a blockchain ecosystem and lack of awareness of the tourist actors in relation to the importance of blockchain technology. The employment of blockchain technology should be a strategic challenge in tourism development of the Macedonian economy.

On the basis of the situation in both countries, we can generally draw the conclusion that efforts should be focused on the creation of the favorable blockchain ecosystem which will open the door for the implementation of blockchain technology modes in the transformation of business models, especially in the tourism industry in both countries. Based on the current situation in both countries, we hope that this paper will initiate further academic research, but also that it will influence the practitioners to start thinking about implementing blockchain technology in the tourism industry.

Our future research aims to measure the impact of blockchain technology on tourism output in Croatia following Croatia's membership in the blockchain partnership at the EU level and further examine the infrastructure for the implementation of blockchain in Macedonia. Another potential research direction could be to introduce ManuChain and MakerChain possibilities into the tourism sector, especially for the purpose of providing high-quality products as souvenirs in both countries.

Author Contributions: Conceptualization, A.E., J.D.S. and I.K.; methodology, A.E.; formal analysis, A.E., J.D.S. and I.K.; investigation, A.E., J.D.S. and I.K.; resources, J.D.S. and I.K.; writing-original draft preparation, A.E.; writing-review and editing, A.E., J.D.S. and I.K.; visualization, A.E., J.D.S. and I.K.; supervision, A.E. All authors have read and agreed to the published version of the manuscript.

Funding: This research received no external funding.

Conflicts of Interest: The authors declare no conflict of interest.

\section{References}

1. Cooper, C.; Fletcher, J.; Gilbert, D.; Shepherd, R.; Wanhill, S. Tourism: Principles \& Practices, 2nd ed.; Longman: Essex, UK, 1999.

2. World Travel and Tourism Council. Global Economic Impact and Trends. Available online: https: //www.wttc.org/economic-impact/country-analysis/ (accessed on 10 September 2019).

3. Persaud, A.; Azhar, I. Innovative mobile marketing via smartphones: Are consumers ready? Mark. Intell. Plan. 2012, 30, 418-443. [CrossRef]

4. Colombo, E.; Bagiio, R. Tourism distribution channels. In Knowledge Transfer to and Within Tourism (Bridging Tourism Theory and Practice); Scott, N., De Martino, M., Van Niekerk, M., Eds.; Emerald Publishing Limited: Bingley, UK, 2017; Volume 8, pp. 289-301.

5. Zsarnoczky, M. The digital future of the tourism \& hospitality industry. Boston Hosp. Rev. 2018, 6, 1-10.

6. IT Chronicles. Blockchain Technology Moves into the Hospitality Industry. Available online: www. itchronicles.com/technology/blockchain-technology-moves-hospitality-industry/ (accessed on 10 April 2019).

7. Madanoglu, M.; Kizildag, M.; Ozdemir, O. Which bundles of corporate governance provisions lead to high firm performance among restaurant firms? Int. J. Hosp. Manag. 2018, 72, 98-108. [CrossRef]

8. Ozdemir, O.; Kizildag, M. Does franchising matter on IPO performance? An examination of underpricing and post-IPO performance. Int. J. Contemp. Hosp. Manag. 2017, 29, 2535-2555. [CrossRef]

9. Iansiti, M.; Lakhani, K.R. The Truth About Blockchain. Harv. Bus. Rev. 2017, 95, 118-127.

10. Kumar, A.; Liu, R.; Shan, Z. Is Blockchain a Silver Bullet for Supply Chain Management? Tech. Chall. Res. Oppor. Decis. Sci. 2019, 1-30. [CrossRef]

11. Rejeb, K.; Rejeb, A. Blockchain Technology in Tourism: Applications and Possibilities. World Sci. News 2019, 137, 119-144.

12. Gjerding, K. How Blockchain Technology Will Dominate the Travel Sector. Available online: www.forbes.com/sites/forbesfinancecouncil/2017/03/28/how-blockchain-technology-will-dominatethe-travel-sector/\#4f16b4d99de5 (accessed on 26 January 2020).

13. Aitken, G. Blockchain Startup TamTam Eyes Trillion Dollar Travel Industry Offering 'Crypto'. Available online: www.forbes.com/sites/rogeraitken/2016/11/01/blockchain-startup-tamtam-eyes-trillion-dollar-travelindustry-offering-crypto/\#4986cb5f2b76 (accessed on 26 January 2020). 
14. Kowalewski, D.; McLaughlin, J.; Hill, A.J. Blockchain Will Transform Customer Loyalty Programs. Available online: https://hbr.org/2017/03/blockchain-will-transform-customer-loyalty-programs (accessed on 26 January 2020).

15. Ozdemir, A.I.; Ar, I.M.; Erol, I. Assessment of blockchain applications in travel and tourism. Ind. Qual. Quant. 2019, 53, 1-15. [CrossRef]

16. Nam, K.; Dutt, C.S.; Chathoth, P.; Khan, M.S. Blockchain technology for smart city and smart tourism: Latest trends and challenges. Asia Pac. J. Tour. Res. 2019, 2-15. [CrossRef]

17. Felin, T.; Lakhani, K. What problems will you solve with blockchain? MIT Sloan Manag. Rev. 2018, 60, 32-38.

18. Bitcoin. Bitcoin: A Peer-to-Peer Electronic Cash System. Available online: https://bitcoin.org/bitcoin.pdf (accessed on 17 September 2019).

19. Seffinga, J.; Lyons, L.; Bachman, A. The Blockchain (R)evolution-The Swiss Perspective; Deloitte: Zurich, Switzerland, 2017; pp. 1-39.

20. Damoska Sekuloska, J.; Erceg, A. Employment of the Smart Contracts in the Practicing of the Franchising Business Model. In Proceedings of the 1st International Conference Applied Computer Technologies, Ohrid, Macedonia, 21-23 June 2018.

21. Swan, M. Blockchain: Blueprint for a New Economy; O’Reilly Media: Cambridge, MA, USA, 2015.

22. Wright, A.; De Filippi, P. Decentralized Blockchain Technology and the rise of Lex Cryptographic. Social Science Research Network. 2015. Available online: https://ssrn.com/abstract=2580664 (accessed on 10 September 2019).

23. Wardynski and Partners. Blockchain, Smart Contracts and DAO. Available online: http://www.codozasady.pl/ wp-content/uploads/2016/11/Wardynski-and-Partners-Blockchain-smart-contracts-and-DAO.pdf (accessed on 17 August 2019).

24. Deloitte. Blockchain Technology: A Game-Changer in Accounting? Available online: https://www2.deloitte.com/content/dam/Deloitte/de/Documents/Innovation/Blockchain_A\%20gamechanger\%20in\%20accounting.pdf (accessed on 10 October 2019).

25. Peters, G.W.; Panayi, E. Understanding modern banking ledgers through blockchain technologies: Future of transaction processing and smart contracts on the internet of money. Soc. Sci. Res. Netw. 2016, 1-33. [CrossRef]

26. Dogru, T.; Mody, M.; Leonardi, C. Blockchain Technology \& its Implications for the Hospitality Industry. Boston Hospitality Review. Available online: https://www.bu.edu/bhr/2018/02/13/blockchain-technology-itsimplications-for-the-hospitality-industry/ (accessed on 20 August 2019).

27. Sanchez, D.C. Raziel: Private and Verifiable Smart Contracts on Blockchains. Available online: https: //arxiv.org/pdf/1807.09484.pdf (accessed on 18 August 2019).

28. Underwood, S. Blockchain beyond Bitcoin. Commun. ACM 2016, 59, 15-17. [CrossRef]

29. Clack, C.D.; Bakshi, V.A.; Braine, L. Smart contract templates: Foundations, design landscape and research directions. arXiv 2016, arXiv:1608.0077.

30. Boucher, P.; Nascimento, S.; Kritikos, M. How blockchain technology could change our lives. In European Parliamentary Research Service, Scientific Foresight Unit; European Parliament: Brussels, Belgium, 2017; pp. 1-28.

31. Schlegel, M.; Zavolokina, L.; Schwabe, G. Blockchain technologies from the consumers' perspectives: What is there and why should who care? In Proceedings of the 51st Hawaii International Conference on System Sciences, Waikoloa Village, HI, USA, 3-6 January 2018; pp. 3477-3486. [CrossRef]

32. Pilkington, M. Blockchain technology: Principles and applications. In Research Handbook on Digital Transformations; Xavier Olleros, F., Zhegu, M., Eds.; Edward Elgar Publishing: Cheltenham, UK, 2015; pp. 225-253.

33. Fortune Magazine. Why Big Business Is Racing to Build Blockchain. Available online: https://finance.yahoo. com/news/why-big-business-racing-build-103053112.html (accessed on 15 November 2019).

34. Nash, S.K. Wal-Mart Turns to Blockchain for Tracking Pork in China. Available online: https://blogs.wsj.com/ cio/2016/10/19/wal-mart-turns-to-blockchain-for-tracking-pork-in-china/ (accessed on 13 October 2019).

35. Wu, H.; Cao, J.; Yang, Y.; Tung, C.L.; Jiang, S.; Tang, B.; Liu, Y.; Wang, X.; Deng, Y. Data Management in Supply Chain Using Blockchain: Challenges and a Case Study. In Proceedings of the 2019 28th International Conference on Computer Communication and Networks, Valencia, Spain, 29 July-1 August 2019; pp. 1-8.

36. Gatteschi, V.; Lamberti, F.; Demartini, C.; Pranteda, C.; Santamaría, V. Blockchain and Smart Contracts for Insurance: Is the Technology Mature Enough? Future Internet 2018, 10, 20. [CrossRef] 
37. Jiang, S.; Cao, J.; Wu, H.; Yang, Y.; Ma, M.; He, J. BlocHIE: A BLOCkchain-Based Platform for Healthcare Information Exchange. In Proceedings of the 2018 IEEE International Conference on Smart Computing, Taormina, Italy, 18-20 June 2018; pp. 49-56.

38. Liao, D.-Y.; Wang, X. Applications of Blockchain Technology to Logistics Management in Integrated Casinos and Entertainment. Informatics 2018, 5, 44. [CrossRef]

39. Tripathi, S. Blockchain application in Media and Entertainment. In Proceedings of the SMPTE 2018, Los Angeles, CA, USA, 22-25 October 2018; pp. 1-8.

40. Davidson, S.; De Filippi, P.; Potts, J. Disrupting Governance: The New Institutional Economics of Distributed Ledger Technology. Available online: https://ssrn.com/abstract=2811995 (accessed on 5 November 2019).

41. Jiang, S.; Cao, J.; McCann, J.A.; Yang, Y.; Liu, Y.; Wang, X.; Deng, Y. Privacy-Preserving and Efficient Multi-Keyword Search over Encrypted Data on Blockchain. In Proceedings of the 2019 IEEE International Conference on Blockchain, Atlanta, GA, USA, 14-17 July 2019.

42. Önder, I.; Treiblmaier, H. Blockchain and tourism: Three research propositions. Ann. Tour. Res. 2018, 72, 180-182. [CrossRef]

43. Kwok, A.O.J.; Koh, S.G.M. Is blockchain technology a watershed for tourism development? Curr. Issues Tour. 2018, 1-6. [CrossRef]

44. BTCWires. The Three Generations of the Blockchain Technology. Available online: https://www.btcwires. com/block-o-pedia/the-three-generations-of-the-Blockchain-technology/ (accessed on 15 November 2019).

45. Coin Insider. What Are the Three Generations of Blockchain, and How Are they Similar to the Web? Available online: https://www.coininsider.com/threegenerations-of-Blockchain/ (accessed on 10 September 2019).

46. Shahab, S.; Allam, Z. Reducing transaction cost of tradable permit schemes using Blockchain smart contracts. Growth Chang. 2019, 1-7. [CrossRef]

47. BTC Manager. TUI Tourism Group Will Adopt Ethereum Blockchain Technology. Available online: https://btcmanager.com/tui-tourism-group-to-adopt-ethereums-blockchain/ (accessed on 17 September 2019).

48. Forbes. Blockchain Startup TamTam Eyes Trillion Dollar Travel Industry Offering 'Crypto'. Available online: https://www.forbes.com/sites/rogeraitken/2016/11/01/blockchain-startup-tamtam-eyes-trillion-dollartravel-industry-offering-crypto/\#1f3012782b76 (accessed on 10 September 2019).

49. PricewaterhouseCoopers. Global Digital IQ Survey: Blockchain. Available online: http://usblogs.pwc.com/ emerging-technology/2017-digital-iq-blockchain/ (accessed on 10 September 2019).

50. Coindesk. Deloitte: 3 Out of 4 Big Companies See 'Compelling' Case for Blockchain. Available online: https: //www.coindesk.com/deloitte-3-out-of-4-big-companies-see-compelling-case-for-blockchain/ (accessed on 17 September 2019).

51. Koo, C.; Park, J.; Lee, J.N. Smart tourism: Traveler, business and organizational perspectives. Inf. Manag. 2017, 54, 683-686. [CrossRef]

52. Willie, P. Can all sectors of the hospitality and tourism industry be influenced by the innovation of Blockchain technology? Worldw. Hosp. Tour. Themes 2019, 11, 112-120. [CrossRef]

53. Kizildag, M.; Dogru, T.; Zhang, T.; Mody, M.; Altin, M.; Ozturk, A.; Ozdemir, O. Blockchain: A paradigm shift in business practices. Int. J. Contemp. Hosp. Manag. 2019. [CrossRef]

54. Preece, J.D.; Easton, J.M. A Review of Prospective Applications of Blockchain Technology in the Railway Industry. Preprint submitted to Int. J. Railw. Technol. 2019, 1-22. [CrossRef]

55. Winding Tree. Winding Tree. Available online: https://windingtree.com/ (accessed on 26 January 2020).

56. Cool Cousins. About Us. Available online: https://www.coolcousin.com/stories/about-us/ (accessed on 26 January 2020).

57. Deskbell Chain. About Us. Available online: https://deskbell.io/about (accessed on 26 January 2020).

58. Travelchain. Travelchain. Available online: https://travelchain.io/ (accessed on 26 January 2020).

59. Flightdelay. Fizzyby Axa. Available online: https:/fizzy.axa/en-gb/faq (accessed on 26 January 2020).

60. Webjet. How Rechain Works. Available online: https://www.rezchain.com/how-rezchain-works/ (accessed on 26 January 2020).

61. Ministry of Tourism of the Republic of Croatia. Strategy for the Development of Croatian Tourism by 2020. Available online: https://mint.gov.hr/UserDocsImages/dokumenti/Strategija-turizam-2020-veljaca2013.pdf (accessed on 18 December 2019). 
62. Ministry of Tourism of the Republic of Croatia. Analysis of Tourist Traffic in July and August and January-August 2019. Available online: https://mint.gov.hr/UserDocsImages/AA_2018_c-dokumenti/190910_ Rezultati.pdf (accessed on 29 December 2019).

63. Ministry of Tourism of the Republic of Croatia. The Most Important $20 \%$ Increase in Tourism Spending. Available online: https://mint.gov.hr/vijesti/cappelli-najvazniji-je-20-postotni-porast-turisticke-potrosnje/ 20750 (accessed on 5 January 2020).

64. Poslovni. Croatia Remains the Only One in the Union Outside the European Blockchain Partnership. Available online: http://www.poslovni.hr/komentari/hrvatska-i-dalje-jedina-u-uniji-izvan-europskog-blockchainpartnerstva-353016 (accessed on 3 January 2020).

65. HINA. Declaration of Co-Operation Signed Establishing a European Blockchain Partnership in Croatia. Available online: http://www.novilist.hr/Znanost-i-tehnologija/Tehnologija/Potpisana-izjava-o-suradnjikojom-se-u-Hrvatskoj-uspostavlja-Europsko-partnerstvo-za-blockchain (accessed on 3 January 2020).

66. UTO: Hospitality and Tourism. New Technologies: How Is Blockchain Changing Tourism? Available online: http://www.utm.hr/?pgid=39\&vid=1112 (accessed on 3 January 2020).

67. ICTBusiness. Rijeka Marketplace Brings Tourism to the Digital World with the Use of Blockchain. Available online: https://www.ictbusiness.info/internet/rijeka-marketplace-donosi-turizam-u-digitalnom-svijetu-uzkoristenje-blockchaina (accessed on 5 January 2020).

68. Peceny, U.S.; Urbančič, J.; Mokorel, S.; Kuralt, V.; Ilijaš, T. Tourism 4.0: Challenges in Marketing a Paradigm Shift. Intechopen 2019. [CrossRef]

69. United Nations World Tourism Organization. International Tourism Highlights; UNWTO: Madrid, Spain, 2019.

70. State Statistical Office of the Republic of Macedonia. Tourist Arrivals and Overnights in the Republic of Macedonia. Available online: http://makstat.stat.gov.mk (accessed on 11 September 2019).

71. World Travel and Tourism Council WTTC. Macedonia, Annual Research: Key Highlights. Available online: https://www.wttc.org/economic-impact/country-analysis/country-reports/ (accessed on 14 September 2019).

72. WEF. The Travel \& Tourism Competitiveness Report 2019: Travel and Tourism at a Tipping Point, World Economic Forum, Geneva. Available online: http://www3.weforum.org/docs/WEF_TTCR_2019.pdf (accessed on 18 September 2019).

73. Ministry of Economy. National Tourism Strategy Republic of Macedonia 2016-2021. Available online: http://economy.gov.mk/Upload/Documents/Kohl\%20\&\%20Partner_Tourism\%20Strategy\% 20Macedonia_DRAFT\%20FINAL\%20REPORT_16\%2002\%2023_E.pdf (accessed on 22 September 2019).

74. National Bank of the Republic of Macedonia. 11th Conference on Payments and Market Infrastructure. Available online: http://www.nbrm.mk/ns-newsarticle-zapocna-11-konferencija-za-plakana-i-pazarnainfrastruktura-na-nbrm-en.nspx (accessed on 23 September 2019).

75. Fintechnews. Blockchain Hong Kong Ecosystem Map. Available online: https://fintechnews.hk/8603/ blockchain/blockchain-hong-kong-ecosystem-map-2019/ (accessed on 17 September 2019).

76. E-SPINcorp. Pros and Cons of Blockchain Technology. Available online: https://www.e-spincorp.com/2017/ 11/24/pros-and-cons-of-blockchain-technology/ (accessed on 29 December 2019).

77. Leng, J.; Yan, D.; Liu, Q.; Xu, K.; Leon Zhao, J.; Shi, R.; Wei, L.; Zhang, D.; Chen, X. ManuChain: Combining Permissioned Blockchain with a Holistic Optimization Model as Bi-Level Intelligence for Smart Manufacturing. IEEE Trans. Syst. Mancybern. Syst. 2020, 50, 182-192. [CrossRef]

78. Leng, J.; Jiang, P.; Xu, K.; Liu, Q.; Leon Zhao, J.; Bian, Y.; Shi, R. Makerchain: A blockchain with chemical signature for self-organizing process in social manufacturing. J. Clean. Prod. 2019, 234, 767-778. [CrossRef]

(C) 2020 by the authors. Licensee MDPI, Basel, Switzerland. This article is an open access article distributed under the terms and conditions of the Creative Commons Attribution (CC BY) license (http://creativecommons.org/licenses/by/4.0/). 